\title{
GROWING MATERIALS: EXPLORING NEW DESIGN PRACTICES TOWARDS A SUSTAINABLE FASHION SECTOR
}

\author{
DOI: 10.35530/TT.2021.24
}

\author{
E. D’Itria*, P. Bolzan, F. Papile
}

Department of Design, Politecnico di Milano, Italy

(E-mail: erminia.ditria@polimi.it, patrizia.bolzan@polimi.it, flavia.papile@polimi.it)

\begin{abstract}
Today, sustainability is an imperative for industry, in all its sectors. The common focus is on achieving development that meets the needs of the present without compromising the future of the Planet and its People.

In the field of fashion and textiles, this momentum toward sustainability translates also into an embryonic process of transformation of the material dimension. This positive transformation is characterized by the choice of new textile solutions supported by growing investments, radical experimentation, and a strong commitment to sustainability. Within this framework, there is a growing interest in bio-based materials, not only from material engineering experts, but also from designers who are starting to explore the possibilities offered by these materials through experiments more focused on design and aesthetics. According to the presented scenario, the proposed article investigates how to strategically implement the systematization of experiments in order to promote the development of an efficient and effective production chain for the growth of bacterial cellulose (BC). To do so, the authors will draw on the knowledge reservoir produced by the DeFORMA project - of which they are all members. This project has just initiated experimentation around the systematization of growth processes and characterization of bacterial cellulose. Specifically, the materials and methods used during the project's initial research phases will be here introduced and illustrated.
\end{abstract}

Keywords: bio-based materials; digital fabrication; fashion design; industrial transformation; sustainability

\section{INTRODUCTION}

Today, Fashion finds itself in an era of transformation of the material dimension, and the driver behind the choice of new textile solutions is growing investment, radical experimentation, and a firm commitment to sustainability. Precisely, the theme of sustainability can be addressed according to different interpretations, which can touch the aspects of design, process, material and distribution, but also cultural and perceived. The modern spirit of textile innovation is characterised by the expansion of synthetic and reengineered fibres. Within this framework, there is a growing interest in bio-based materials, not only by materials experts with an engineering background, but also in a relevant way by designers [1-4], who are exploring the possibilities offered by these materials through experiments more focused on the design and aesthetic aspects. This industry is one of the largest industrial sectors in the world. The fashion supply chain is dynamic and complex, extending over several tiers including design, raw material production, manufacturing, distribution, and collection. The commitment to textile research and development should come as no surprise. On one hand, fashion industry needs to address its impacts as it is considered a key contributor to several environmental and social issues. Its negative action 
is reported all along its supply chain from the production process to consumer disposal [57]. Here, particular attention is paid to the stages in the procurement process and manufacturing flows. According to Chaves and Villalobos (2021) the industry is responsible for exploitation of natural resources, energy consumption, waste production, CO2 emission, indiscriminate use of synthetic materials, among others [8]. Quantis reported that apparel and footwear industries account for $8 \%$ of the world's greenhouse gas emissions, almost as much as the total carbon impact of the EU. The apparel industry alone accounts for $6.7 \%$ of the world's greenhouse gas emissions, with more than 50\% coming from 3 phases: fibre production (15\%), yarn preparation (28\%), and the highest impact phase - dyeing \& finishing (36\%) [9]. About water usage, almost 93 billion cubic metres of water are consumed every year in the garment industry, which could be enough to satisfy the needs of 5 million people. In addition, around $20 \%$ of the world's wastewater is the direct result of dyeing and fabric treatment practices. Often at the end of the cycle, this untreated wastewater is pumped back into our water systems, contaminating its contents with toxins and heavy metals [10]. Furthermore, textiles are the largest source of primary micro plastics (specifically manufactured to be smaller than $5 \mathrm{~mm}$ ), accounting for $34.8 \%$ of global micro plastic pollution [11]. In parallel with these environmental aspects, social aspects cannot be neglected. As discussed by Mukherjee (2015), the industry has an important role in nurturing an unfair system based on globalisation, vulnerability of global capital and subsequent volatile employment opportunities in the developing countries, growing feminization of the workforce, workers' rights, their health and safety, among the others [12]. On the other hand, Fashion is a cultural and creative industry which has as its main objective the production or reproduction, the promotion, distribution or commercialization of goods, services and activities of content derived from cultural, artistic or heritage origins [13]. Thus, Fashion industry combines two separate dimensions: an intangible - its cultural, artistic or heritage origins - with a tangible one. This material medium through which to express all these meanings is precisely the textiles. Because materials serve as this medium, their role is critical. It is therefore not surprising that fashion is intransigent when it comes to fabrics. Aesthetic-symbolic parameters become fundamental when choosing a particular material: even a small change can have a big impact on the selection of that material [14]. Considering the importance of materials in the fashion industry, it is easy to see why textiles are a fertile ground for experimentation. Specifically, the last few years have seen an increasing interest around biomaterials. This because brands search for more sustainable alternatives against their environmental and social impacts. Wider trends are further contributing to this interest such as climate change, the potential for lower carbon footprints, the will to abandon fossil based synthetic materials, and the war on plastics [14]. Thus, the next big thing in fashion could be bio-based materials as they are focusing the industry attention, as well as shaping its sustainable future [1]. In this context, the paper explores the innovative character of the project De_FORMA. De_FORMA (Design Explorations on bioFabricated ORganic MAterials) research project aims to support the shift of focus from the simple growth of the crop to its planning and design in relation to possible applications. By building a material from scratch, it is possible to modify the traditional processing chain, anticipating needs and constraints currently left to post-production. This could enable new production and business paradigms.

\section{DEFINING BIOS}

Today, bio-based textiles are catalysing sustainable innovation efforts in material development. Increasingly more companies and designers are starting to work on radical and green innovations for the production of naturally-based materials characterized by 
sustainable performances. Several research and development opportunities are therefore being pursued in the bio-based materials area. Of these many opportunities available for fashion designers, this paper will focus on a specific dimension: the bio-fabricated materials, which, thanks to their intrinsic characteristics of sustainability and flexibility, offer new ways of thinking about conventional textile manufacturing. But what a biofabricated material is? To define it, the terminology about biomaterials and their derivates has been adapted from the biomedical field, but the authors select the interpretation that fits more for the fashion industry. According to this, the definition adopted is the one proposed by Biofabricate and Fashion for Good in their last report "Understanding 'bio' material innovation". This report considers everything falling under the umbrella term "biomaterial". All biomaterials are bio based but the biological component can largely vary from less than $10 \%$ to $100 \%$ [15] (figure 1 ).

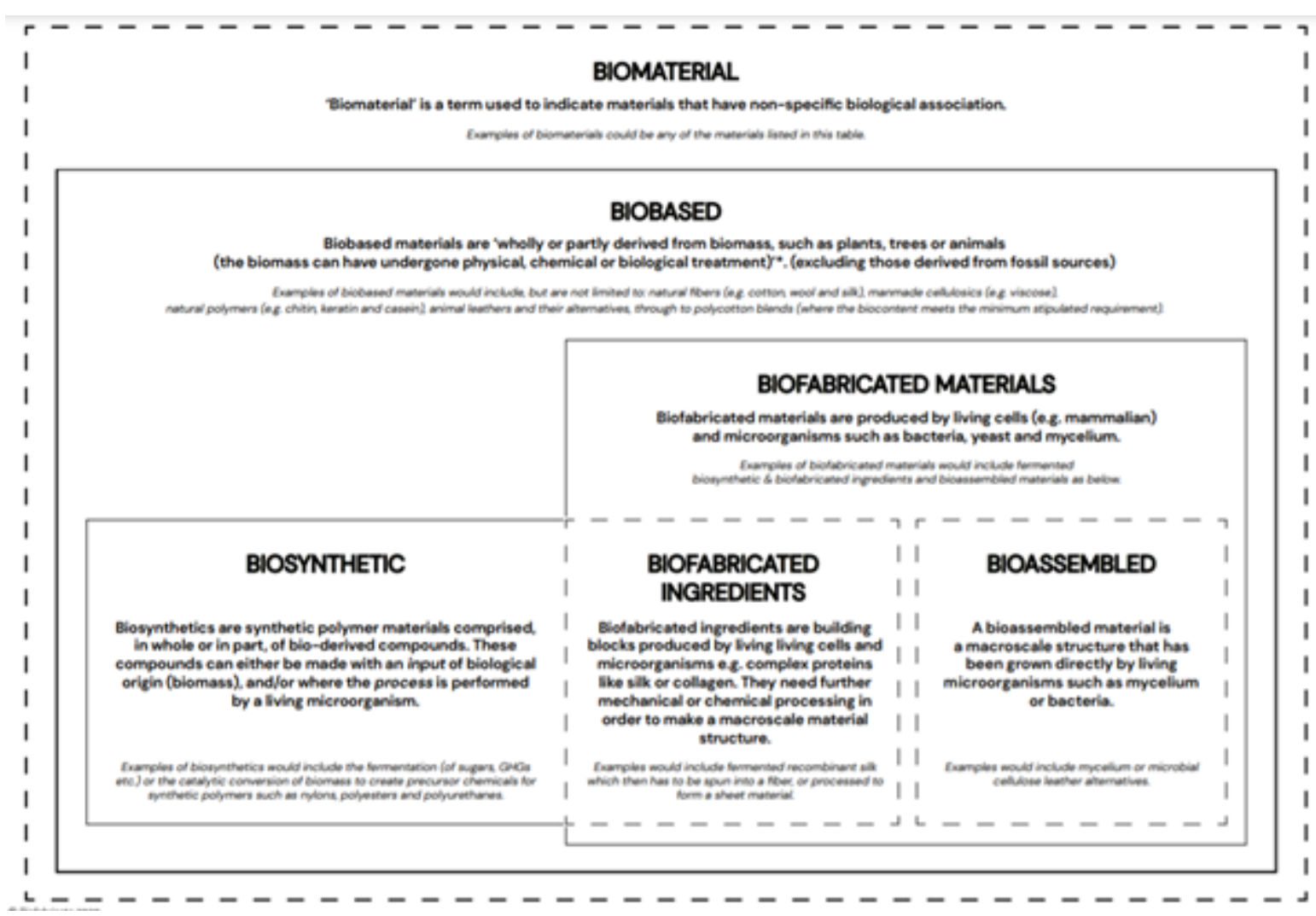

Figure 1. 'Defining Bio’ Biofabricate and Fashion for Good, UNDERSTANDING "BIO” MATERIAL INNOVATION: a primer for the fashion industry, December 2020

Bio-fabricated material is "the production of complex living and non-living biological products from raw materials such as living cells, molecules, extracellular matrices, and biomaterials." [15]. This kind of materials cover two sub-categories: Biofabricated ingredients and bio-assembled materials. Bio-fabricated ingredients "are building blocks produced by living cells and microorganisms e.g. complex proteins like silk or collagen. They need further mechanical or chemical processing in order to make a macroscale material structure"[15]. Bio-assembled material "is a macroscale structure that has been grown directly by living microorganisms such as mycelium or bacteria” [15]. The present work focuses on one specific bio-assembled material: the bacterial cellulose (BC). As discussed by Amorin, BC is composed of cellulose nanofibers secreted extracellularly by 
some bacteria [16]. This is an innovative raw material characterized by ecological, renewable and organic properties $[17,18]$. BC has a high degree of crystallinity, tensile strength, thermal stability, biodegradability, elasticity and porosity [19]. Furthermore, it is to be safe for contact with the human body [17].

$\mathrm{BC}$ appearance, which is similar to leather, allows it to be considered as a new type of sustainable fabric that can be manufactured from several sources [17]. Despite the interesting characteristics of bacterial cellulose, there is still no systematization of the several experimentations and the possibility of scaling up the one-off experiments into a systematized process for the fashion industry seems yet a long-term perspective. BC is inherently sustainable as it is renewable and biodegradable, but current experiments do not consider the production system from the perspective of circularity, integration, and optimization with potential applications.

\section{MATERIALS AND METHODS}

According to the aforementioned issues, the authors are part of a research group in Politecnico di Milano that launched experimentation around the systematization of growth processes and characterization of BC. The experimentation explores and verifies the mutual collaboration between bio-manufacturing processes and Digital Fabrication (DF) through the filter of design as a holistic discipline. These are the premises from which the De_FORMA project was born. Through the use of DF as an enabler for the construction of ecosystems for the cultivation of BC, De_FORMA aims to explore the possibility of constructing an experimental and flexible production system. The developed system could allow innovative practices such as a prior integration of formal choices, surface/aesthetic treatments, and additional elements, in a logic of zero waste. Methodologically the project follows four consecutive phases to produce iterative knowledge: (1) theoretical analysis, (2) research methodologies, (3) experimental verification of evidences, (4) dissemination of results. The whole process is being conducted in a systematic way, including the analysis and evaluation of results and errors. Now, the project is in progress and heading towards the conclusion of the third step with mature crops being hacked to understand the possibilities offered to the designers. The first step (1) was a theoretical analysis of the state of the art to frame BC research and design opportunities. This analysis phase allowed an exploration of $\mathrm{BC}$ evolution through an in depth literature review and mapping of case studies. The case studies were all best practices that have distinguished themselves for their work on two specific dimensions. Some case studies focus their work on enhancing growth processes in terms of production (e.g. culture techniques, morphogenesis, and processes), integration (e.g. other materials, colours, sensors, and actuators), and application (e.g. fashion, health, and lighting). Other case studies work on production chains in the DF context. Furthermore, this step has led to identifying inferences between GM and process and product design. The second step (2) aimed at defining a set-up for bacterial cellulose culture. The methodology applied to carry out this second step was akin with the experimental research [20] which creates a filter for the systemic analysis of the causal relationships between the variables involved, such as: growth of the material, manufacturing process(es) and insertion of components within the material itself. This dichotic process of controlling and monitoring was repeated in an iterative manner and supported by the application of techniques and processes typical of the design activity (design and realisation of tools, supports and prototypes). As a result, a suitable configuration for the culture of bacterial cellulose was identified. The third step is currently happening and is based on experimental verification of the evidence for the formulation of replicable standards. In this phase (3), empirical tests are 
carried out to verify the processes of culture and growth of BC and its hybridisation with other materials and/or sensors, in order to define and evaluate possible fields of application. Various set-ups are being defined and applied for the culture of BCs, to be monitored according to qualitative and quantitative parameters (e.g. time and homogeneity of growth, olfactory quality). The monitoring of the growth process, is allowing understanding how to intervene through ad-hoc systems and instruments, realised using DF technologies present in the laboratories involved in the project (figure 2). This further step will now allow to define material and formal characterisation variables, with particular attention to surface qualities (e.g. texture and flexibility), optical qualities (e.g. transparency and colour), volumetric qualities (e.g. thickness), and the relative technical profile.

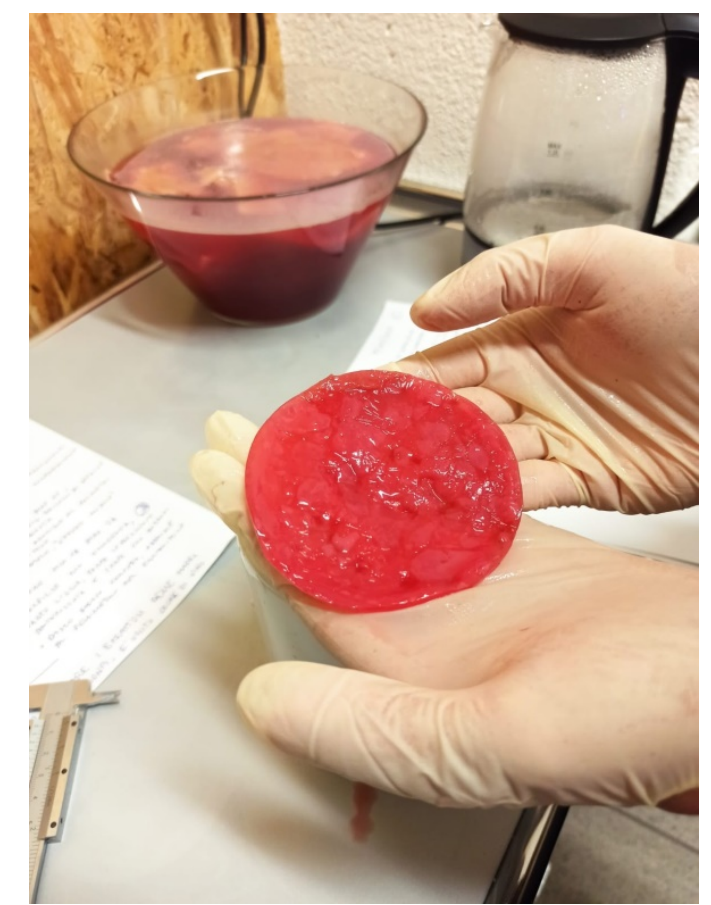

Figure 2. BC monitoring. Credit: De_FORMA project (2021)

In this context, the heterogeneous competences of the teammates are functionally used as a resource to identify possible fields of application and to support the next and last step of the project which aims at the dissemination of the findings.

\section{RESULTS AND DISCUSSIONS}

In regard to the broader investigative picture conducted in De_FORMA, the contribution focuses on the strategy implemented for the systemization of experiments, in order to promote the development of an efficient and effective production chain for the growth of bacterial cellulose. In detail, through the use of digital fabrication, it is possible to prototype pilot experiences on a small scale, to test the real feasibility of some insights, such as the approach to a zero-waste production system, the integration of additional elements during the growth of the material, the a priori design of the aesthetic and perceptual parameters of the material. Thanks to the use of additive manufacturing, it was possible to create growth chambers specifically designed to optimize some fundamental steps that bacterial cultures require. Just the redesign of these elements within the prototyping of the production chain has made it possible to make the growth of the material more efficient and controllable the final result. As designers, the 
components of sustainability and quality and attention to aesthetics are crucial when conducting materials investigations. From the sustainability point of view, Although GMs are inherently sustainable as they are renewable and biodegradable, current experiments do not consider the production system in terms of circularity, integration and optimization with potential applications. We frequently witness a design exercise, which does not consider the applicative and functional evidence of the material's technical, sensory and intangible characteristics. De_FORMA wants to be the missing link between this experimental trend and the concrete possibility of transforming bacterial cellulose into a material that can be integrated into sustainable production chains and re-produced according to stable effective systems. In this sense we can recognize a level of attention to environmental sustainability:

- of the material, which is bio-based and pre-designed to avoid the generation of subsequent waste;

- of the production process, which adopts Digital Fabrication as an enabler, thus using organic polymers;

- of the impact on the application fields, for example, counteracting the impact that is being recorded in the textile sector (due to fast-fashion), or in the lighting and consumer electronics sector (with regard to the disassembly and recycling of components).

Transforming the traditional manufacturing processes through design thinking and digital fabrication has implications in terms of cultural sustainability in the definition of new knowledge useful to be encoded in new open-ended knowledge systems. Besides, De_FORMA project focuses on the programmability and assessment of the aesthetic features of the bio-manufactured living materials, functionalized to the application in the initial design stages. The aesthetics dimension is closely dependent both on functional aspects and sensory perception. Working on the intrinsic characterization of a "living" and "growing" material is a significant and attractive challenge for designers, who can operate on colonies of bacteria/yeasts to encode the aesthetic aspects of the final biofabricated material (figure 3).

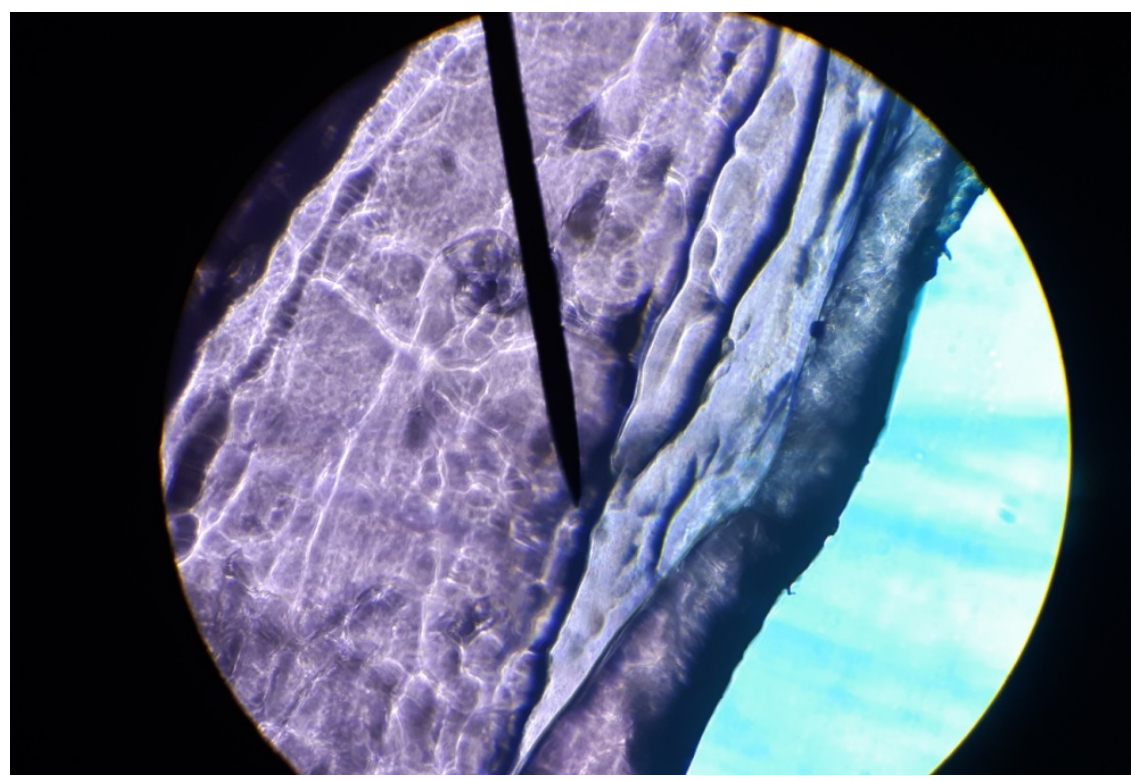

Figure 3. BC "growing" material enlarged under the microscope. Credit: De_FORMA project (2021). 
The aesthetic aspects, on which it is intended to intervene, because relevantly perceived by users in contact with the finished product, are:

- surface qualities, e.g. consistency, flexibility, texture;

- optical qualities, e.g. transparency, colours, photoluminescence;

- volumetric qualities, e.g. thickness and weight.

When sensors and actuators are integrated into the material, it will be able to transform itself according to predefined inputs or to variation of parameters subject to direct monitoring, creating in fact a "smart" material, whose aesthetic features are dynamic and programmable. The characteristics of the scoby to be water resistant but not waterproof once dried, ensures easy disassembly of electronic components from the smart material, promoting its environmental sustainability at the end of its life cycle. The whole growing process will offer practitioners a direct feedback on materials properties, showing the direct correlation and interdependence between conceptual ideas and real-life ones. In this way, the aesthetic of a single material will become an expression of the process itself and of the cooperation between designers and other beings, increasing awareness of prime matter use and design. Aesthetics evaluation will be performed taking into account users' tactile, visual, and olfactory ex periences along with assessing their emotional and intangible impact. To further all these aspects, the best geometries for the construction of the growth chambers are currently still being tested, as well as different mediums in which to grow BC in the shortest time and with the best aesthetic quality.

\section{NEW POSSIBLE SCENARIOS}

Within the vision of scaling up the production process of these promising materials, the systematisation of experiments, procedures and process monitoring are basic steps to ensure an appropriate starting point for producing grown bacterial cellulose on a larger scale [6]. Certain studies [21,22] affirm that the gestation time between the discovery of a new material and its widespread commercialisation may present a gestation time of about 20 years in average. To speed up this process, it becomes fundamental to build a concept with the innovation, demonstrate its potential and formally being approved into, e.g., new products to access the market [23]. Imagining growing materials as industrial level products or semi-products requires, then, a well-known data and an accurate repeatability for the production process itself. Defining some standards to be maintained all along the production line is fundamental to envision the application of $\mathrm{BC}$ as a material for the fashion industry. Therefore, the properties and intrinsic qualities of the grown material need to be accurately measured, but also material behaviour under operational processes and compatibility with other materials as well will be analysed Also, an accurate reflection on the possibility to reuse the material at the end of product's life could be an interesting insight on which future works could be addressed. However, whatever the purpose of the investigation it will be, it, becomes mandatory to start with the characterisation of the obtained materials towards technical, sensorial, aesthetical and sustainability properties analysis, to effectively envision the grown $\mathrm{BC}$ as a candidate alternative in the competitive market of materials for design, and specifically, for the fashion industry. In this perspective, future works on the project will focus on the material characterisation with a particular attempt to correlate production process and material properties, creating a portfolio of possible combinations, or enlightening the procedures to grow materials with already intended properties. 


\section{CONCLUSIONS}

Given the initial results collected and the reflections made on possible future application scenarios, a program for the development of the experiment has been outlined.

The innovative character of the project De_FORMA lies in the shift of attention from the simple growth of the crop to its programming and design, depending on possible applications. By building material from scratch, it will be possible to modify the traditional production chain, anticipating needs and constraints that are currently delegated to postproduction. This could enable new productive and entrepreneurial paradigms. The participants in the project, although they all have a background that can be associated with the discipline of Design, come from very divergent fields of research and practice, giving a strong added value of multidisciplinary. The transversal know-how of the participants offers a synergistic intersection able to enhance, integrate and develop knowledge, converging on methods, tools and models. In summary, the innovative character of De_FORMA is to have addressed a topic related to the growth of microorganisms with a design approach. The ultimate aim of the project is to expand the material production potential in view of design and circular economy, embracing a sustainable development perspective and following the material biological cycle.

Although the experiments have not yet reached a level of maturity, we can already confirm some of the insights gained at the beginning of the project, while other optimizations have not yet been achieved. In particular, the idea of making products completely zero waste starting from the use of this material has not yet found a viable solution in a standardized and effective way: this is because during the drying phases, the edges of the $\mathrm{BC}$ assume greater rigidity and a different colour than the rest of the piece. For this reason the project cannot yet be said to be concluded and scalable, although interesting observations have already been developed that are producing two derived lines: one starting from the intrinsic chromatic changes of the material, one from the reuse of filaments considered as waste. Current evidence is suggesting that the development of strategies around BC can lead to a deep systemic renewal of the production cycle of new materials all to be designed, thanks also to the typical design culture of designers.

\section{ACKNOWLEDGEMENTS}

Participants in the De_FORMA research project, funded within the Farb and MiniFarb calls by the Department of Design of Politecnico di Milano, are: Patrizia Bolzan (coordinator), Daria Casciani, Erminia D’Itria, Flavia Papile, Stefano Parisi, Barbara Pollini and Carlo Emilio Standoli.

\section{REFERENCES}

[1] Bof-Mckinsey, State of Fashion 2020, Available at: https://www.mckinsey.com/ /media/McKinsey/Industries/Retail/Our\%20Insights/The\%20state\%20 of\%20fashion\%202020\%20Navigating\%20uncertainty/The-State-of-Fashion-2020-final.ashx [Accessed on June 2021]

[2] A New Textiles Economy: Redesigning Fashion's Future. Available at: https://www.ellenmacarthurfoundation.org/assets/downloads/publications/A-New-Textiles-

Economy_Full-Report_Updated_1-12-17.pdf [Accessed on July 2, 2021]

[3] Camere, S., Karana, E., Fabricating materials from living organisms: An emerging design practice, In: Journal of Cleaner Production, 2018, 186, 570-584

[4] Mihaleva, G., Bio matter in creative practises for fashion and design, In: AI \& Soc, 2020, https://doi.org/10.1007/s00146-020-00957-5 
[5] da Silva, C.J.G., de Medeiros, A.D.M., de Amorim, J.D.P., et al., Bacterial cellulose biotextiles for the future of sustainable fashion: a review, In: Environ Chem Lett, 2021, 19, 2967-2980, https://doi.org/10.1007/s10311-021-01214-x

[6] Laavanya, D., Shirkole, S., Balasubramanian, P., Current challenges, applications and future perspectives of SCOBY cellulose of Kombucha fermentation, In: Journal of Cleaner Production, 2021, 295, 126454, https://doi.org/10.1016/j.jclepro.2021.126454

[7] Shafie, S., Kamis, A., Ramli, M.F., Abu Bedor, S., Ahmad Puad, F.N., Fashion Sustainability: Benefits of Using Sustainable Practices in Producing Sustainable Fashion Designs, In: International Business Education Journal, 2021, 14, 1, 103-111, https://doi.org/10.37134/ibej.vol14.1.9.2021

[8] Chaves, B.L., Villalobos, A.S., Sustainable Fashion. In: Gardetti M.Á., Larios-Francia R.P. (eds) Sustainable Fashion and Textiles in Latin America, In: Textile Science and Clothing Technology, Springer, Singapore, 2021, https://doi.org/10.1007/978-981-16-1850-5_15

[9] Measuring Fashion: Insights from the Environmental Impact of the Global Apparel and Footwear Industries, Available at: https:/quantis-intl.com/report/measuring-fashion-report/ [Accessed on August 14, 2021]

[10] Fast Fashion's Environmental Impact: The True Price Of Trendiness, Available at: https://goodonyou.eco/fast-fashions-environmental-impact/ [Accessed on August 14, 2021]

[11] Boucher, J., Friot, D., Primary Microplastics in the Oceans: A Global Evaluation of Sources, IUCN, 2017, Available at: https://portals.iucn.org/library/sites/library/files/documents/2017-002En.pdf [Accessed on August 14, 2021]

[12] Mukherjee, S., Environmental and Social Impact of Fashion: Towards an Eco-friendly, Ethical Fashion, In: Journal of Interdisciplinary and Multidisciplinary Studies (IJIMS), 2015, 2, 3, 22-35

[13] What do we Mean by the Cultural and Creative Industries?, Available online: https://unstats.un.org/unsd/iiss/The-UNESCO-Framework-for-Cultural-Statistics-FCS.ashx

[Accessed on August 14, 2021]

[14] Richetti, M., Neomateriali nell'economia circolare, Moda. Ediz. a colori, Milano: Edizioni Ambiente, 2017

[15] Lee, S., Congdon, A., Parker, G, Borst, C., Understanding 'Bio' Material Innovations. A primer for the Fashion industry, In: Biofabricate \& Fashion for Good, 2020

[16] Amorim, J.D.P., Souza, K.C., Duarte, C.R., Duarte, I.S., Ribeiro, F.A.Z., Silva, G.S., Farias, P.M.A., Stingl, A., Costa, A.F.S., Vinhas, G.M., Plant and bacterial nanocellulose: production, properties and applica-tions in medicine, food, cosmetics, electronics and engineering. A review, In: Environ Chem Lett, 2020, 18, 851-869

[17] Sederavičiūtè, F., Bekampienè, P., Domskienè, J., Effect of pretreatment procedure on properties of Kombucha fermented bacterial cellulose membrane, In: Polymer Testing, 2019, 78, 105941

[18] Shi, Z., Zhang, Y., Phillips, G.O., Yang, G., Utilization of bacterial cellulose in food, In: Food hydrocolloids, 2014, 35, 539-545

[19] Machado, R.T., Meneguin, A.B., Sábio, R.M., Franco, D.F., Antonio, S.G., Gutierrez, J., Barud, H.S., Komagataeibacter rhaeticus grown in sugarcane molasses-supplemented culture medium as a strategy for enhancing bacterial cellulose production, In: Industrial Crops and Products, 2018, 122, 637-646

[20] Bang, A.L., Eriksen, M.A., Experiments all the way in programmatic design research, In: Artifact, 2014, 3, 2, 1-4

[21] Eagar, T.W., Bringing new materials to market, In: Technology Review, 1995, 98, 2, $42-49$

[22] Karana, E., Barati, B., Rognoli, V., Zeeuw Van Der Laan, A., Material driven design (MDD): A method to design for material experiences, 2015

[23] Markham, S.K., Moving technologies from lab to market, In: Research-technology management, 2002, 45, 6, 31-42 